\title{
Total Diz Artroplastisinde Kalça ve Diz Eklem Hareket Açıklığı ile Kas Kuvveti Ölçümünün Subjektif Fonksiyonel Sonuçlar Üzerine Etkisi
}

\author{
Effect of Hip and Knee Joint Range of Motion and Muscle Strength on Subjective \\ Functional Outcomes in Total Knee Arthroplasty
}

\author{
Emrah Çalışkan, Volkan İğdir \\ Sağlık Bilimleri Üniversitesi, Ankara Bilkent Şehir Hastaneleri Ortopedi Ve Travmatoloji Kliniği \\ Yazıșma Adresi / Correspondence: \\ Volkan İğdir \\ Üniversiteler Mahallesi, Bilkent Bulvarı. No: 1, Çankaya/Ankara \\ T: + $905443280803 \quad$ E-mail : volkanigdir7@gmail.com \\ Geliş Tarihi / Received : 25.07.2019 Kabul Tarihi / Accepted : 18.11.2019 \\ Orcid : \\ Emrah Çalışkan https://orcid.org/: 0000- 0001- 5500- 6571 \\ Volkan İğdir https://orcid.org/0000- 0002- 7599- 8923 \\ ( Sakarya Tip Dergisi / Sakarya Med J 2019, 9(4):652-660 ) DOI: 10.31832/smj.596740
}

\footnotetext{
Öz

Amaç Primer diz artroplastisi öncesi ve sonrası kas kuvveti ve eklem hareket açkllı̆ı (EHA) ölçümünün klinik subjektif fonksiyonel skorlar ile korelasyonunu inceleyerek subjektif fonksiyonel sonuçlar üzerindeki etkinliğini belirlemektir.

Gereç ve Primer diz artroplastisi uygulanan 26 hasta (23K/3E) prospektif olarak takip edildi. Ortalama yaș 67,3 yll (aralık, 50-81 yll), ortalama takip süresi 16 ay (aralık 6-24 Yöntemler ay). 14 (\% 53,8) hastanın sol tarafı, 12 (\% 46,2) hastanın ise sağ tarafı opere edildi. Operasyondan 1 gün önce ve postoperatif 6 . ayda diz ve kalça EHA ve kas kuvveti ölçümleri yapıldı. EHA ölçümü için standart gonyometre kas kuvveti ölçümü için ise el dinamometresi kullanıldı. Ölçümlerle es zamanlı olarak klinik subjektif fonksiyonel değerlendirme için Amerikan Diz Cemiyeti (ADC) diz ve fonksiyon skoru ile Oksford Diz Skoru (ODS) kullanıld. Hem preoperatif hem de postoperatif ölçümler ve skorlar arasındaki ilişki incelendi. İstatistiksel analiz için SPSS versiyon 21'de gruplar arası fark Student T ve Wilcoxon Testleri ile, korelasyon analizi ise Pearson ve Spearman testleri ile gerçekleștirildi.

Bulgular Postoperatif dönemde preoperatif döneme göre tüm subjektif fonksiyonel skorlamalarda, kalça fleksiyonunda ve fleksiyon kuvvetindeki artıș anlamlı bulundu ( $\mathrm{p}=0,010$, $\mathrm{p}=0,021)$. Postoperatif kalça fleksiyon, kalça ekstansiyon hareket açıllıkları ve preoperatif kalça abduksiyon kuvveti ile tüm postoperatif subjektif fonksiyonel skorlamalar arasinda pozitif korelasyon belirlendi $(\mathrm{p}<0,05)$.

Sonuç Sonuç olarak bu çalışma ile total diz artroplastisinde postoperatif kalça fleksiyon açıklığı ve fleksiyon kuvvetinin fonksiyonel durumu diğer objektif ölçümlere göre daha iyi yansıttı̆̆ı; ayrıca preoperatif kalça abduksiyon kuvvetinin postoperatif subjektif iyileșme ile korele olduğu gözlendi.

Anahtar Diz artroplastisi; eklem hareket açıklı̆̆ı kas kuvveti; kalça; diz

kelimeler

Abstract

Objective The aim of this study was to determine the effectiveness of muscle strength and range of motion (ROM) on subjective fuctional outcomes before and after primary knee arthroplasty and to investigate their correlations with clinical subjective functional scores.

Materials The study was composed of prospectively followed-up 26 patients $(23 \mathrm{~F} / 3 \mathrm{M})$ who underwent primary knee arthroplasty. The mean age was 67,3 years (range, 50-81 years), the mean follow-up and Methods period was 16 months (range, 6-24 months). Left side of 14 (53,8\%) patients and right side of 12 patients (46,2\%) were operated. Knee and hip ROM and muscle strength were measured 1 day before operation and 6 months postoperatively. Standard goniometer and hand held dynomometer was used for ROM and muscle strength measurements respectively. Simultaneously with the measurements, American Knee Society (KSS) knee and function score and Oxford Knee Score (OKS) were used for clinical subjective functional evaluation. The relationship between both preoperative and postoperative measurements and scores was examined. The difference between the groups was analysed by Student $T$ and Wilcoxon tests, and correlation analysis was performed by Pearson and Spearman tests via SPSS version 21.0.

Results In the postoperative period, all subjective functional scores, range of hip flexion motion and hip flexor muscle group strength were significantly higher than preoperative period (p=0,010, $p=0,021$ ). Postoperative range of hip flexion and extension motion and preoperative hip abductor muscle group strength were positively correlated with all postoperative subjective functional scores $(p<0.05)$

Conclusion As a result, in this study, postoperative range of hip flexion motion and hip flexor muscle group strength in total knee arthroplasty reflects functional status better than other objective measurements; In addition, preoperative hip abductor muscle group strength was correlated with postoperative subjective recovery.

Key words Knee replacement; range of motion; muscle strength; hip; knee
} 


\section{GIIRIŞ}

Osteoartrit; eklem kıkırdağının ve çevre yumuşak dokuların hasarı ile seyreden, en sık diz eklemini tutan dejeneratif bir eklem hastalığıdır. Hastalığın primer klinik yansıması ağrı ve hareket kısıtlılığı, öncelikli tedavisi konservatif yöntemlerdir. Konservatif tedaviye rağmen çoğu vakada ağrı ve aktivite kısıtlılı̆̆ı ilerleyip fonksiyonel bozukluk meydana gelebilmektedir. ${ }^{1}$ Konservatif tedavi yöntemlerine yanıt alınamayan olgularda yüksek tibial osteotomi, unikondiler diz artroplastisi veya total diz artroplastisi (TDA) gibi cerrahi seçenekler uygulanmaktadır. Bunlar arasında en sık TDA uygulanmaktadır. ${ }^{2}$ TDA ile temel amaç ağrıyı azaltmak, eklem hareket açıklığını artırmak ve hareket kabiliyetini geliştirmektir. ${ }^{3}$ Cerrahi teknik ve implant teknolojilerindeki gelişmelere rağmen, TDA operasyonu sonrasında bazı hastalar; kronik ağrı, eklem hareket kısıtlılığ1 ve kas güçsüzlüğüne sekonder aktivite kısıtlılığ1 bildirmekte ve sonuçta bu hastalarda fonksiyonel bozukluk devam etmektedir. ${ }^{4-6} \mathrm{Bu}$ durum da TDA sonrasinda subjektif fonksiyonel sonuçların ve objektif ölçümlerin değişiklik göstermesine neden olmaktadır.

TDA' dan sonra fonksiyonel değişiklikleri değerlendirmek için Oksford Diz Skoru (ODS) gibi izole anket skorlamaları veya Amerikan Diz Cemiyeti (ADC) skoru gibi anket ve fizik muayenenin birlikte değerlendirildiği subjektif skorlamalar kullanılmaktadır. ${ }^{7,8}$ Fonksiyonel sonuçları objektif olarak değerlendirmek için eklem hareket açıklığı (EHA) ve kas kuvveti ölçümünün kullanılabileceğini öneren çalışmalar olmakla birlikte, bu ölçümlerin subjektif fonksiyonel sonuçlarla korele olup olmadığı tartışmalıdır. Alnahdi $\mathrm{AH}$ ve ark. unikondiler diz protezi yapılan hastalarda kalça abduktor kuvveti ile subjektif fonksiyonel sonuçlar arasında pozitif korelasyon olduğunu tespit ettiği çalışmalarında kas kuvveti ölçümünün fonksiyonel sonuçları gösterebileceğini düşünmektedirler. ${ }^{9}$ Benzer şekilde Mizner ve ark. kuadriseps kas kuvveti ölçümünün fonksiyonel sonuçlarla yüksek korelasyon gösterdiğini tespit etmişlerdir. ${ }^{10} \mathrm{~V}$. Wyldea ve ark. ise preoperatif EHA ölçümünün fonksiyonel değerlendirme için kullanılmasını önermezken, Shuichi
Matsuda ve ark. EHA ölçümünün subjektif sonuçlarla pozitif korelasyon göstereceğini savunmaktadırlar., ${ }^{5,11}$

Hipotezimiz subjektif fonksiyonel sonuçlar üzerinde kas kuvveti ölçümünün EHA ölçümüne göre daha etkili olduğudur. Bu çalışma ile primer diz artroplastisi öncesi ve sonrası kas kuvveti ve EHA ölçümünün klinik subjektif fonksiyonel skorlar ile korelasyonunu inceleyerek subjektif fonksiyonel sonuçlar üzerindeki etkinliğini belirlemek amaçlanmıştır.

\section{GEREÇ ve YÖNTEMLER}

Bir müdahale araştırması olan bu çalışmada etik kurul onayı alınmasını takiben (E. Kurul- E-17-1325); Ankara Numune Eğitim ve Araştırma Hastanesinde 22.05.2017 ile 19.04.2019 tarihleri arasında diz osteoartriti tanısı alan hastalardan konservatif tedavi ile şikayetleri gerilemeyen ve primer total diz artroplastisi ameliyatı uygulanan 26 hasta (23 K [\%88.5] /3 E [\%11.5]) prospektif olarak takip edildi. Ortalama yaş 67,3 yıl (aralık, 50-81 yıl), ortalama takip süresi 16 ay (aralık 6-24 ay), ortalama vücut kitle in-

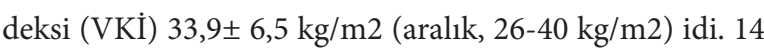
$(\% 53,8)$ hastanın sol tarafi, 12 (\% 46,2) hastanın ise sağ tarafı opere edildi. Tüm hastalardan aydınlatılmış onam alındı. 50 yaşından küçük, desteksiz mobilize olamayan, preoperatif fizik tedavi görmeyen hastalar, nörodejeneratif veya vasküler patolojisi bulunan, alt ekstremite de operasyon geçmişi olan, postoperatif takip protokolüne uymayan hastalar çalışma dışında tutuldu.

Tüm hastaların preoperatif ön- arka ve yan diz grafileri ile tanjansiyel patella grafileri çekildi. Radyolojik olarak osteoartritin şiddetini belirlemek için Kellgren- Lawrence sınıflaması kullanıldı ve bu sınıflamaya göre tüm hastalar evre 4 gonartroz olarak değerlendirildi. ${ }^{12}$ Ayrıca ekstremite uzunluğunu değerlendirmek için bacak uzunluk grafisi (ortoröntgenogram), vertebral patolojileri dişlamak için skolyoz grafileri çekildi. Hiçbir hastada alt ekstremite uzunluk farkı veya skolyoz saptanmadı. 
Kalça ve diz aktif EHA' sı; kontralateral kalça ve diz eklemi tam ekstansiyonda ve orta hatta iken pelvik hareket olmaksızın kolları $26 \mathrm{~cm}$ standart gonyometre ile Amerikan ortopedik cerrahlar akademisinin önerdiği nirengi noktaları baz alınarak üçer kez ölçüldü ve ortalamaları kaydedildi.13-15 Kas kuvveti ölçümleri el dinamometresi (Baseline ${ }^{\bowtie}$ Lite Hydrolic Hand Dynamometer) ile arada el yapımı bir aparat kullanılarak "make test" tekniği uygulanarak yapıld1. ${ }^{16-18}$ Kalça ekstansiyon, fleksiyon, abduksiyon ve adduksiyon kuvveti hasta supin pozisyonda yatarken, diz fleksiyon ve ekstansiyon kuvveti ise kalça ve diz eklemi 90 derece fleksiyondayken hastanın elleri havada pelvik harekete izin vermeden her hasta için 5 saniye bekleyebildiği maksimum kas kontraksiyonu baz alınarak 3 kez ölçüldü ve ortalaması kaydedildi. (Figür 1).

Hastaların subjektif fonksiyonel sonuçları ise ADC ve ODS skorlama sistemleri kullanılarak değerlendirildi. ADC skorlaması iki kısımdan oluşmaktadır. Birinci kısım diz skoru olarak adlandırılmakta ve ağrı, eklem hareket açıklığı, anatomik dizilim ile stabilite temelli puanlama yapılıp, 60 puan ve altı kötü, 60-70 arası orta, 70-80 arası iyi, 80 puan ve üzeri mükemmel olarak değerlendirilmekte; ikinci kısım ise fonksiyon skoru olarak adlandırılmakta ve yürüme mesafesi, merdiven inip çıkma ve baston-yürüteç gibi yürüme desteği ihtiyacına göre fonsiyonel değerlendirme yapılıp; 0 ile 100 arasında puanlanmaktadır. ${ }^{19}$ ODS ise ağrı ve fonksiyonel durumu sorgulayan 12 soruluk tek bir kısımdan oluşmaktadır ve 0-48 aralığında puanlandırılmaktadır. 0-19 puan şiddetli diz artriti, 20-29 puan orta-şiddetli diz artriti, 30-39 puan hafif-orta diz artriti, 40-48 puan ise tatmin edici eklem fonksiyonu olarak değerlendirilmektedir. ${ }^{20}$ ODS’ nin Türkiye için validasyonu mevcutken, ADC' nin Türk validasyonu yoktur. ${ }^{21}$

Çalışmadaki tüm objektif fonksiyonel ölçümler ve subjektif fonksiyonel skorlamalar tek bir cerrah tarafindan, operasyondan bir gün önce ve postoperatif 6.ayda yapılmıştır. Hastaların tamaminda operasyona antibiyotik profilaksisini takiben (Sefazolin 2 gr/ iv), turnike hemostazında, orta hat longitudinal cilt insizyonu ve medial parapatellar artrotomi ile başland1. ${ }^{22}$ Patella laterale devrildi, parsiyel sinoviektomi ve patellar denervasyon yapıldı, osteofitler temizlendi. Arka çapraz bağ muayene ile değerlendirildi ve tüm hastalara fleksiyonda uygun femoral ve tibial kesiler yapıldıktan sonra posterior stabilize komponentler antibiyotikli çimento eşliğinde yerleştirildi. Çimentonun donmasını takiben turnike açıldı, yıkama, kanama kontrolü yapılarak 1 adet hemovak dren konuldu ve katlar anatomik olarak kapatıldı. Operasyon ortalama $75 \mathrm{dk}$ (aralık 50-100 dk) sürdü. Postoperatif antibiyotik profilaksisine 24 saat devam edildi. Operasyon sonrası 1. günde hemovak drenin çekilmesini takiben, sürekli pasif hareket cihazı ile 1 saat pasif diz eklem hareketi yaptırıldı. ${ }^{23}$ Ardından aktif kalça, diz, ayak bileği egzersizleri başlanarak yürüteç eşliğinde hastalar mobilize edildi. Takiplerinde majör komplikasyon ile karşılaşılmayan hastalar postoperatif ortalama 4. günde (aralık 3-7 gün) taburcu edildi. Tüm hastalara en az 1 aylık derin ven trombüsü (DVT) ve arteriyel emboli profilaksisi (Düşük molekül ağırlıklı heparin 6000 IU/ 0,6 ml, orta basınç anti emboli çorabı ) verildi. ${ }^{24}$ Tüm hastalar için total diz artroplastisi sonrası klasik rehabilitasyon protokolü uyguland1. ${ }^{25}$ Üçüncü hafta kontrolde süturlar alındı ardından hastalar 6. hafta, 3. ay ve 6. ayda tekrar değerlendirildi. Tüm kontrollerde hemogram, C-Reaktif Protein (CRP), Eritrosit Sedimentasyon Hızı (ESH), diz anteriorposterior ve lateral grafi değerlendirildi. Kontrollerde 4 hastada asemptomatik CRP ve ESH yüksekliği, 1 hastada yüzeyel cilt enfeksiyonu saptandı, uygun takip ve tedaviler verildi. Hiçbir hastada takip sürecinde sekonder operasyon yapılmadı. Tüm hastaların operasyonları ve postoperatif takipleri tek bir cerrah tarafindan yapıldı.

İstatistiksel analiz SPSS versiyon 21.0 (IBM Corp., Armonk, NY, USA) ile yapıldı. Verilerin normal dağılım gösterip göstermediği görsel (Histogram ve olasılık grafikleri) ve analitik (Shapiro-Wilk testleri) yöntemlerle değerlendirildi. Normal dağılım gösteren değişkenler ve tanımlayıcı istatistikler için ortalama $\bigotimes$ standart sapma verildi ve parametrik olmayan testler için ise medyan (minimummaksimum) değerleri verildi. Normal dağılan veriler için başlangıç ve 6.ay arası iki zamanda yapılan karşılaştırmalar 
bağımlı gruplar Student T testi kullanılarak karşılatırıldı. Normal dağılmayan verilerin kıyaslanması için Wilcoxon testi kullanıldı. Korelasyon analizi için parametrik dağılan veriler için Pearson testi, non-parametrik veriler için ise Spearman analizi yapıldı. Örneklem sayısının 25 olduğu durumda \%80 güç ve \%95 güven aralığı elde edilmiştir. $\mathrm{P}$ değerinin $0,05^{\prime}$ in altında olduğu durumlar istatistiksel olarak anlamlı sonuçlar şeklinde değerlendirildi.

\section{BULGULAR}

Preoperatif ve postoperatif subjektif skorlamaların ve objektif ölçümlerin ortalamaları tablo 1, 2 ve 3’te özetlenmiştir. (Tablo 1, 2, 3).

\begin{tabular}{|l|c|c|c|}
\hline \multicolumn{4}{|c|}{$\begin{array}{c}\text { Tablo 1: Preoperatif ve postoperatif subjektif fonksiyonel skor } \\
\text { ortancaları ve değişimin korelasyonu }\end{array}$} \\
\hline $\begin{array}{c}\text { Subjektif } \\
\text { fonksiyonel skor }\end{array}$ & $\begin{array}{c}\text { Preoperatif } \\
\text { Ortanca } \\
\text { (EKD-EBD) }\end{array}$ & $\begin{array}{c}\text { Postoperatif } \\
\text { Ortanca } \\
(\text { EKD-EBD) }\end{array}$ & p değeri \\
\hline ADC- diz & $39,5(27-71)$ & $91(78-100)$ & $<\mathbf{0 , 0 0 1}$ \\
\hline ADC- fonksiyon & $25(10-80)$ & $90(70-100)$ & $<\mathbf{0 , 0 0 1}$ \\
\hline ODS & $10(4-25)$ & $42(26-48)$ & $<\mathbf{0 , 0 0 1}$ \\
\hline
\end{tabular}

ADC: Amerikan Diz Cemiyeti, ODS: Oksford Diz Skoru, EKD:

En küçük değer, EBD: En büyük değer

Preoperatif ADC diz skoru 1 (\% 3,8) hastada iyi, 25 (\% $96,2)$ hastada kötü, ODS ise 3 (\% 11,5) hastada orta, 23 (\% $88,5)$ hastada kötü bulunmuşken; postoperatif ADC diz skoru 1 (\% 3,8) hastada iyi, 25 (\% 96,2) hastada mükemmel, ODS ise $1(\% 3,8)$ hastada orta, $7(\% 26,9)$ hastada iyi, 18 (\% 69,3) hastada mükemmel bulunmuştur. Postoperatif dönemde preoperatif döneme göre tüm subjektif fonksiyonel skorlamalardaki (ADC- diz skoru, ADC- fonksiyon skoru ve ODS) artış anlamlı bulunmuştur $(p<0,001)$. ( Tablo 1) EHA ölçümlerinden sadece kalça fleksiyonu $(\mathrm{p}=0,010)$ ve diz fleksiyonundaki $(\mathrm{p}=0,037)$ artış, kas kuvveti ölçümlerinden ise sadece kalça fleksiyon $(p=0,021)$ ve diz ekstansiyon $(\mathrm{p}=0,015)$ kuvvetindeki artış anlamlı bulundu. (Tablo 2-3).

\begin{tabular}{|c|c|c|c|}
\hline \multicolumn{4}{|c|}{$\begin{array}{l}\text { Tablo 2: Preoperatif ve postoperatif EHAa değerlerinin ortanca } \\
\text { veya ortalaması ile değişimin korelasyonu }\end{array}$} \\
\hline EHA & $\begin{array}{l}\text { Preoperatif } \\
\text { Ortanca } \\
(\text { EKD-EBD) }\end{array}$ & $\begin{array}{l}\text { Postoperatif } \\
\text { Ortanca (EKD- } \\
\text { EBD) }\end{array}$ & $\mathrm{p}$ değeri \\
\hline Kalça fleksiyon & $96,5(70-125)$ & $105(92-115)$ & 0,010 \\
\hline $\begin{array}{l}\text { Kalça ekstansiyon } \\
\text { Ortalama } \pm \text { SS }\end{array}$ & $14,26 \pm 6.16^{*}$ & $16.96 \pm 6.08^{*}$ & 0,033 \\
\hline Kalça abduksiyon & $35(25-47)$ & $36(25-43)$ & 0,380 \\
\hline Kalça adduksiyon & $20(12-31)$ & $17(12-30)$ & 0,011 \\
\hline Kalça iç rotasyon & $28(17-40)$ & $24(18-40)$ & 0,007 \\
\hline $\begin{array}{l}\text { Kalça diş rotasyon } \\
\text { Ortalama } \pm \text { SS }\end{array}$ & $21,75 \pm 6.25^{\star}$ & $13,57 \pm 3.39^{*}$ & 0,614 \\
\hline Diz fleksiyon & $103(72-122)$ & $106,5(60-130)$ & 0,037 \\
\hline Diz ekstansiyon & $3(0-10)$ & $3(1-15)$ & 0,949 \\
\hline \multicolumn{4}{|c|}{$\begin{array}{l}\text { EHA: Eklem Hareket Açıklığı, SS: Standart sapma EKD: En } \\
\text { küçük değer EBD: En büyük değer a: Derece biriminden değeri } \\
\text { *: İfade ettiği değer satır başlığında belirtilmiştir }\end{array}$} \\
\hline
\end{tabular}

\begin{tabular}{|c|c|c|c|}
\hline \multicolumn{4}{|c|}{$\begin{array}{l}\text { Tablo 3: Preoperatif ve postoperatif kas kuvvetlerinina orta- } \\
\text { laması veya ortancası ile değișimin korelasyonu. }\end{array}$} \\
\hline Kas kuvveti & $\begin{array}{c}\text { Preoperatif } \\
\text { Ortanca } \\
\text { ( EKD-EBD) }\end{array}$ & $\begin{array}{l}\text { Post operatif } \\
\text { Ortanca } \\
\text { ( EKD-EBD) }\end{array}$ & $\mathrm{p}$ değeri \\
\hline Kalça fleksiyon & $\begin{array}{c}22,67 \\
(11,33-34,01)\end{array}$ & $\begin{array}{c}24,94 \\
(18,14-38,55)\end{array}$ & 0,021 \\
\hline Kalça ekstansiyon & $\begin{array}{c}13,60 \\
(4,53-38,55)\end{array}$ & $\begin{array}{c}13,60 \\
(3,62-34,01)\end{array}$ & 0,784 \\
\hline Kalça abduksiyon & $\begin{array}{c}22,22 \\
(11,33-36,28)\end{array}$ & $\begin{array}{c}25,17 \\
(13,60-31,75)\end{array}$ & 0,137 \\
\hline Kalça adduksiyon & $\begin{array}{c}20,41 \\
(9,07-36,28)\end{array}$ & $\begin{array}{c}22,67 \\
(12,24-43,09)\end{array}$ & 0,055 \\
\hline Diz fleksiyon & $\begin{array}{c}20,41 \\
(11,33-45,35)\end{array}$ & $\begin{array}{c}18,14 \\
(11,33-36,28)\end{array}$ & 0,556 \\
\hline $\begin{array}{l}\text { Diz ekstansiyon } \\
\text { Ortalama } \pm \text { SS }\end{array}$ & $22,81 \pm 7,54^{*}$ & $2,57 \pm 5,82^{*}$ & 0,015 \\
\hline \multicolumn{4}{|c|}{$\begin{array}{l}\text { a: kg biriminden değer, SS: Standart sapma, EKD: En küçük } \\
\text { değer EBD: En büyük değer }{ }^{*} \text { : İfade ettiği değer satır başlığında } \\
\text { belirtilmiştir }\end{array}$} \\
\hline
\end{tabular}

Preoperatif subjektif fonksiyonel skorlamaların tamamı ile korele preoperatif EHA veya preoperatif kas kuvveti saptanmamıştır. Postoperatif kalça eklemi fleksiyon ve ekstansiyon hareket açıklığı ve postoperatif diz fleksiyon kuvveti ile postoperatif subjektif fonksiyonel skorlamalar arasında pozitif korelasyon belirlenmiştir. Preoperatif subjektif fonksiyonel skorlamaların tamamı ile korele postoperatif 
Sakarya Tip Dergisi 2019;9(4):652-660

ÇALIŞKAN ve Ark., Diz Artroplastisinde Eklem Hareket Açılklı̆ı ve Kas Kuvveti

EHA veya postoperatif kas kuvveti saptanmamıștır. Preoperatif EHA ve preoperatif kas kuvveti ile postoperatif subjektif fonksiyonel skorlar arasındaki ilişki incelendiğinde sadece kalça abduksiyon kuvveti ile tüm skorlamalar arasında pozitif korelasyon saptanmıştır ( $\mathrm{p}<0,050)$. (Tablo 4).

\begin{tabular}{|c|c|c|c|c|c|c|c|c|c|}
\hline \multirow{3}{*}{\multicolumn{4}{|c|}{ Objektif Ölçümler }} & \multicolumn{3}{|c|}{ Preoparatif } & \multicolumn{3}{|c|}{ Postoperatif } \\
\hline & & & & \multicolumn{2}{|c|}{ ADC } & \multirow{3}{*}{$\begin{array}{l}\text { ODS } \\
0,069\end{array}$} & \multicolumn{2}{|c|}{$\mathrm{ADC}$} & \multirow{3}{*}{$\begin{array}{l}\text { ODS } \\
0,199\end{array}$} \\
\hline & & & & \multirow{2}{*}{$\begin{array}{c}\begin{array}{c}\text { Diz } \\
\text { Skoru }\end{array} \\
0,200\end{array}$} & \multirow{2}{*}{$\begin{array}{c}\begin{array}{c}\text { Fonksiyon } \\
\text { Skoru }\end{array} \\
0,956\end{array}$} & & \multirow{2}{*}{$\begin{array}{c}\text { Diz } \\
\text { Skoru }\end{array}$} & \multirow{2}{*}{$\begin{array}{c}\begin{array}{c}\text { Fonksiyon } \\
\text { Skoru }\end{array} \\
0,512 \\
\end{array}$} & \\
\hline \multirow{14}{*}{ 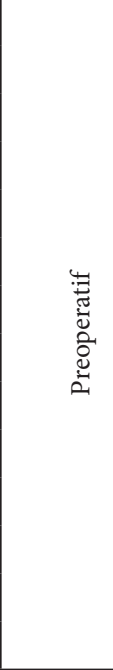 } & \multirow{8}{*}{ EHA } & \multirow{6}{*}{ Kalça } & Fleksiyon & & & & & & \\
\hline & & & Ekstansiyon & 0,048 & 0,054 & 0,015 & 0,050 & 0,254 & 0,190 \\
\hline & & & Abduksiyon & 0,063 & 0,012 & 0,002 & 0,290 & 0,990 & 0,005 \\
\hline & & & Adduksiyon & 0,667 & 0,568 & 0,194 & 0,330 & 0,558 & 0,066 \\
\hline & & & İç Rotasyon & 0,176 & 0,011 & 0,001 & 0,050 & 0,115 & 0,002 \\
\hline & & & Diş Rotasyon & 0,171 & 0,015 & 0,005 & 0,021 & 0,186 & 0,021 \\
\hline & & \multirow{2}{*}{ Diz } & Fleksiyon & 0,164 & 0,717 & 0,702 & 0,460 & 0,941 & 0,062 \\
\hline & & & Ekstansiyon & 0,035 & 0,009 & 0,070 & 0,590 & 0,049 & 0,011 \\
\hline & \multirow{6}{*}{$\begin{array}{c}\text { Kas } \\
\text { Kuvveti }\end{array}$} & \multirow{4}{*}{ Kalça } & Fleksiyon & 0,220 & 0,028 & 0,060 & 0,310 & 0,190 & 0,250 \\
\hline & & & Ekstansiyon & 0,351 & 0,032 & 0,000 & 0,009 & 0,083 & 0,003 \\
\hline & & & Abduksiyon & 0,971 & 0,421 & 0,014 & 0,022 & $<0,001$ & 0,007 \\
\hline & & & Adduksiyon & 0,674 & 0,165 & 0,000 & 0,040 & 0,002 & 0,055 \\
\hline & & \multirow{2}{*}{ Diz } & Fleksiyon & 0,443 & 0,044 & 0,000 & 0,034 & 0,056 & 0,074 \\
\hline & & & Ekstansiyon & 0,471 & 0,740 & 0,041 & 0,450 & 0,563 & 0,058 \\
\hline \multirow{14}{*}{ 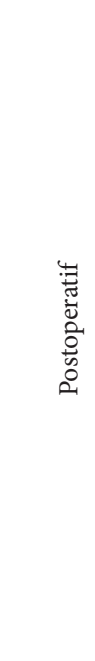 } & \multirow{8}{*}{ EHA } & \multirow{6}{*}{ Kalça } & Fleksiyon & 0,320 & 0,045 & 0,082 & $<0,001$ & 0,016 & 0,002 \\
\hline & & & Ekstansiyon & 0,740 & 0,042 & 0,341 & $<0,001$ & 0,016 & 0,008 \\
\hline & & & Abduksiyon & 0,860 & 0,753 & 0,126 & 0,003 & 0,387 & 0,020 \\
\hline & & & Adduksiyon & 0,430 & 0,890 & 0,231 & 0,269 & 0,074 & 0,082 \\
\hline & & & İç Rotasyon & 0,760 & 0,320 & 0,674 & 0,032 & 0,531 & 0,114 \\
\hline & & & Diş Rotasyon & 0,034 & 0,890 & 0,036 & 0,030 & 0,116 & 0,009 \\
\hline & & \multirow{2}{*}{ Diz } & Fleksiyon & 0,780 & 0,654 & 0,450 & 0,000 & 0,062 & 0,001 \\
\hline & & & Ekstansiyon & 0,397 & 0,430 & 0,543 & 0,570 & 0,103 & 0,160 \\
\hline & \multirow{6}{*}{$\begin{array}{c}\text { Kas } \\
\text { Kuvveti }\end{array}$} & \multirow{4}{*}{ Kalça } & Fleksiyon & 0,420 & 0,320 & 0,765 & 0,152 & 0,193 & 0,160 \\
\hline & & & Ekstansiyon & 0,876 & 0,127 & 0,890 & 0,219 & 0,416 & 0,011 \\
\hline & & & Abduksiyon & 0,038 & 0,840 & 0,460 & 0,361 & 0,840 & 0,256 \\
\hline & & & Adduksiyon & 0,086 & 0,079 & 0,87 & 0,011 & 0,095 & 0,002 \\
\hline & & \multirow{2}{*}{ Diz } & Fleksiyon & 0,031 & 0,039 & 0,065 & 0,001 & 0,008 & 0,010 \\
\hline & & & Ekstansiyon & 0,865 & 0,780 & 0,084 & 0,194 & 0,146 & 0,207 \\
\hline
\end{tabular}



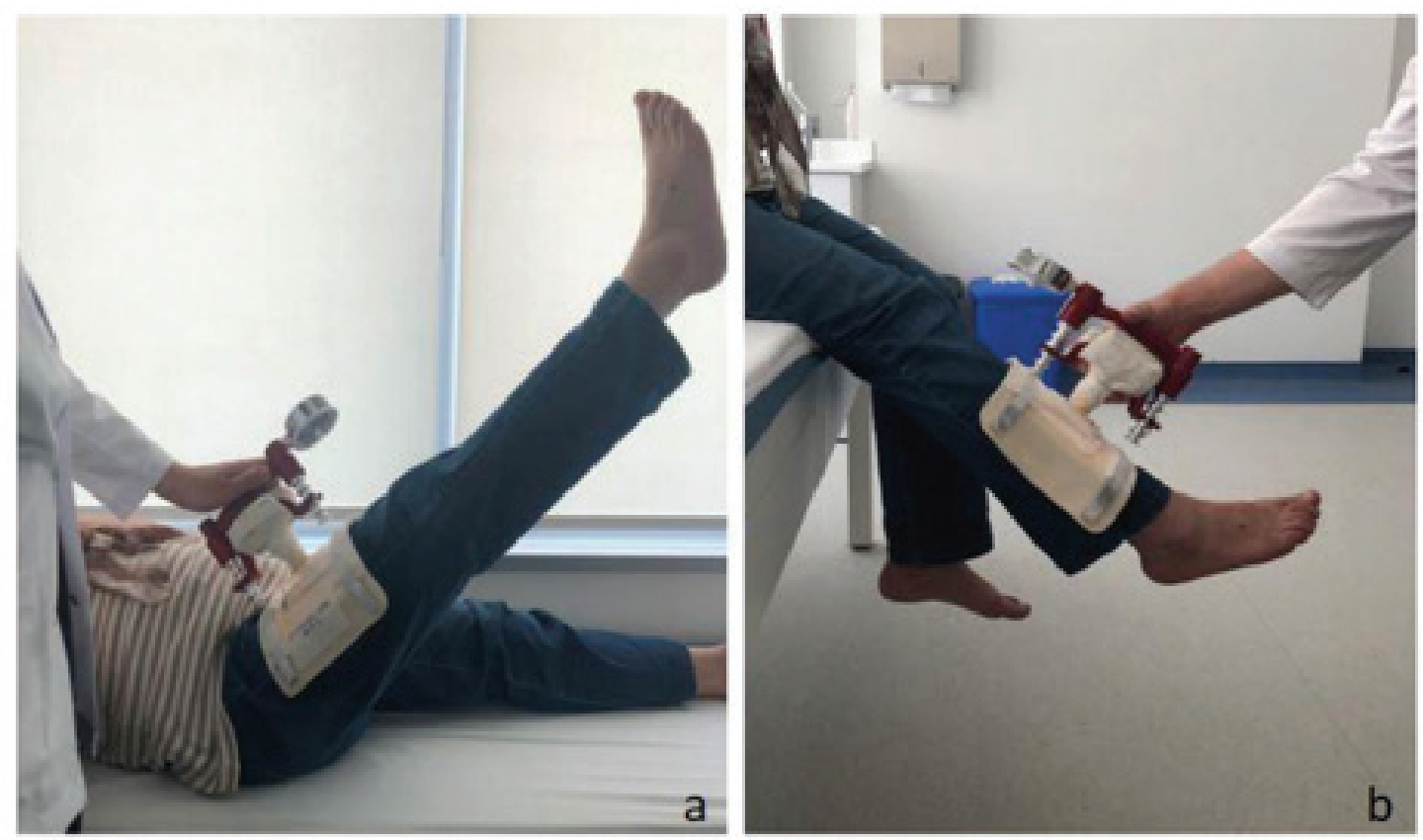

Figür 1: Kalça fleksiyon kuvveti ölçümü (a), diz ekstansiyon kuvveti ölçümü (b).

\section{TARTIŞMA}

$\mathrm{Bu}$ çalışma ile diz artroplastisi öncesi ve sonrası kalça ve diz eklemlerinin hareket açıklığı ve kas kuvvetleri ölçülerek subjektif fonksiyonel skorlamalar ile olan ilişkisi araştırıldı. Daha önceki çalışmalar özellikle sadece diz fleksiyonu veya kuadriseps kas kuvvetinin subjektif sonuçlara etkisini tespit etmeye yönelmişken; ${ }^{26,27}$ bu çalışma ile diz eklemi ile birlikte kalça ekleminin de hareket açıklıkları ve bu iki ekleme etki eden kas kuvvetlerinin subjektif fonksiyonel skorlar ile korelasyonu incelendi.

ADC diz ve fonksiyon skoru ile ODS özellikle diz operasyonları öncesi ve sonrası hastaların fonksiyonel durumunu değerlendirmek için kullanılan subjektif skorlamalardan bazılarıdır. Asif S. ve Choon DS, total diz protezi yapılan 50 hastanın orta dönem sonuçlarını inceledikleri çalışmalarında ADC sistemini kullanmışlar ve ortalama diz skorunu $87 \pm 11,06$; ortalama fonksiyonel skoru $72 \pm$ 20,27 olarak bulmuşlar; $\% 88$ mükemmel, $\% 4$ iyi, $\% 2$ orta ve \%6 kötü sonuç elde etmişler. ${ }^{8}$ Avram SG. ve ark. ise eş zamanlı ve aralıklı olarak bilateral total diz protezi yapılan ve her 2 dizi eş zamanlı opere edilen hastaların sonuçlarının daha iyi olduğunu tespit ettiği 328 hastada fonksiyonel sonuçları ODS ile değerlendirmişlerdir. ${ }^{28} \mathrm{Bu}$ skorlamalar yaygın kullanılmalarına rağmen ölçüm zamanlamalarıyla ilgili literatürde belirgin bir konsensüs yoktur. West JA. ve ark. TDA uygulanan 50 hasta üzerinde yaptıkları prospektif çalışmalarında postoperatif 3 . ay ve 12 . ayda ölçülen ADC ve ODS skorlarında preoperatif döneme göre anlam1 artış saptarken; 3 . ay skorları ile 12. ay skorları arasında anlamlı farklllık saptamamıştır. ${ }^{29}$ Yine Minator Sajjadi M. ve ark. 33 romatoid Artrit (RA) ve 138 Osteoartrit (OA) zemininde TDA uyguladıkları 171 hastalık çalışmalarında postoperatif 6. ay ve 12. ayda ölçtükleri ODS’ de preoperatif döneme göre 2 grupta da anlamlı artış izlemiş, dönemsel karşılaştırma yapıldığında RA grubunda 6 . ay ve 12. ay ölçümleri arasında anlamlı fark izlenmemişken, OA grubunda 12. ayda 6. aya göre ODS anlamlı olarak daha yüksek bulunmuştur. ${ }^{30}$ Literatürde sonuçların analizi için farklı zamanlar görülse de; yara iyileşme sürecinin hücresel düzeyde 6 ay sonunda tamamlanmasını ve ODS skorlama sisteminin tanımlandığı referans çalışmayı da göz 
önüne alarak postoperatif 6 . ayda subjektif ölçümlerimizi gerçekleştirdik. ${ }^{31}$ Sonuçta tüm ölçümlerimizde preoperatif döneme göre literatürle benzer şekilde anlamlı artış tespit ettik.

TDA' nın EHA ve kas kuvveti üzerine etkisi ile ilgili çalışmalar genellikle diz eklemi baz alınarak değerlendirilmiş, kalça eklemine etkisi ise genellikle doğrudan değil de yürüme analizi temelli çalışmalar ile incelenmiştir. ${ }^{32-34}$ Kerrigan DC. ve ark. 31 yaşlı ve 31 genç hasta grubu ile yaptıkları karşılaştırmalı çalışmalarında diz osteoartriti olan yaşlı grupta kalça fleksiyonunun azaldığını, Al-Zahrani KS. ve ark. 58 hasta ile yaptıkları çalışmalarında diz osteoartriti olan hastalarda pelvik eğimin arttığını yürüme analizi ile göstermişlerdir. ${ }^{35,36}$ Biggs PR. ve ark. da 30 hasta üzerine yaptıkları yürüme analizi temelli çalışmalarında artroplasti sonrası kalça fleksiyonunda artış tespit etmişler ve bu durumun artan pelvik eğimin bir sonucu olabileceğini bildirmişlerdir. ${ }^{37}$ Ouellet ve Moffet de 29 hasta ile yaptıkları yürüme analizi temelli çalışmalarında benzer sonuç elde etmişler ve kalça fleksiyonundaki artışın kuadriseps kas zayıflı̆̆ını kompanse etmek için olabileceğini bildirmişlerdir. ${ }^{38}$ Bizim çalışmamızda ise TDA' nın kalça eklemi üzerine etkisi yürüme analizi ile değil doğrudan ölçümlerle değerlendirilmiş ve sonuçta Ouellet ve Biggs PR'. nin çalışmaları ile benzer şekilde kalça fleksiyon açısında ve ayrıca kalça fleksiyon kuvvetinde TDA sonrası anlamlı bir artış izlenmiştir. Bu durum pelvik eğim veya kuadriseps kas zayıflığının kompansasyonu sonucu olabileceği gibi, M. sartorius, M. rectus femoris ve M. tensor fascia lata gibi diz eklemini, osteofit formasyonunun ve kıkırdak aşınmasının daha yoğun olduğu, anterior, lateral ve medialden kateden yardımcı kalça fleksör kas gruplarının osteoartritten daha çok etkilenmesi ve operasyon sonrası bu etkilenmenin ortadan kalkması nedeniyle olabileceğini düşündük.

Literatürde postoperatif döneme ait objektif ölçümlerin büyük kısmını yine diz fleksiyonu ve kuadriseps kuvveti oluşturmaktadır. ${ }^{39,40}$ Maempel JF. ve ark. 5 ila 10 yıl takipli 1036 hasta ile yaptıkları çalışmalarında ise postoperatif
ODS ile diz EHA' nın korele olduğunu belirtmişlerdir. ${ }^{41}$ Kurowicki J. ve ark. unikompartmantal diz protezi yap1lan ve minimum 1 yıl takip ettikleri 26 hastadan oluşan çalışmalarında kuadriseps ve hamstring kas kuvvetindeki artışın ADC' deki artış ile ilişkili bulmuşlardır. ${ }^{42}$ Çalışmamızda birçok objektif ölçümle subjektif skor arasında korelasyonlar tespit edilmesine rağmen özellikle diz fleksiyon kuvveti ile kalça fleksiyon ve ekstansiyon hareket açıklığ1 her 3 skor ile de korele bulunmuştur. Artan kompansatuvar kalça fleksiyonuna sekonder yürüme siklusundaki salınım ve basma fazının koordinasyonun devamı için kalça ekstansor kuvvetleri de kalça fleksorlerini karşılamak durumundadır. Bu da kalça ekstansor kuvvetlerindeki artışı açıklayabilir. Bu nedenle diz artroplastisi sonrası rehabilitasyonda diz eklemine yönelik egzersizlerin yanı sıra kalça fleksiyon ve ekstansiyon açıklığına yönelik egzersizlere de önem vermenin fonksiyonel sonuçları daha da artıracağını düşünmekteyiz.

Preoperatif eklem hareketinin postoperatif subjektif fonksiyonel durum üzerine etkisi halen tartışmalıdır. V.Wyldea ve ark. 249 hasta ile yaptıkları çalışmalarında preoperatif diz fleksiyon- ekstansiyon ile kalça fleksiyon, abduksiyon, adduksiyon, iç ve dış rotasyonu ölçerek postoperatif WOMAC fonksiyonel skalası ile korelasyonunu incelemişler; sonuçta preoperatif EHA' nın postoperatif fonksiyonel durum üzerine etkisinin zayıf olduğunu bildirmişlerdir. ${ }^{11}$ Benzer şekilde Miner AL. ve ark. 684 hasta üzerinde yaptıkları çalışmalarında preoperatif diz fleksiyon ve ekstansiyonun açılarının post operatif WOMAC skoruna etkisinin olmadığını bildirmişlerdir. ${ }^{43}$ Fakat Jiang C. ve ark. ise 72 hasta ile yaptıkları çalışmalarında preoperatif diz EHA' nın post operatif erken dönem fonksiyonel sonuçlar ile korele olduğunu belirtmişlerdir. ${ }^{44}$ Çalışmamızda bazı preoperatif EHA ve kas kuvvetleri ile postoperatif fonksiyonel skorlar arasında ikili korelasyonlar tespit edilmiş; ancak özellikle preoperatif kalça abduksiyon kuvvetinin tüm postoperatif skorlamalar ile korele olduğu gösterilmiştir. Brown M. ve ark. da 107 geriatrik hasta ile yaptığ çalışmalarında diz osteoartriti olan yaşlı hastalarda fonksiyonel performans 
düşüklüğünü kalça abduktorlerinin zayıflığı ile ilişkili bulmuşlardır. ${ }^{45} \mathrm{Bu}$ durum kalça abdüktörlerinin, yürüyüş sırasında gövde ve kalçanın stabilizasyonu, femoro pelvik uyumun sağlanması, femur başı stabilitesinin sağlanması ve kuvvetlerin alt ekstremiteden pelvise aktarılması için birincil kas grubu olmasından kaynaklanıyor olabilir. ${ }^{46,47}$ Dolayısı ile preoperatif kalça abduksiyon kuvvetinin postoperatif fonksiyonel iyileşme üzerine etkisi cerrahi öncesi fizyoterapide abduksiyon kuvvetine yönelik egzersizlerin önemini göstermektedir.

Çalışmamızda bir takım kısıtlılıklar mevcuttur. Bunlardan birincisi örneklem sayısının azlı̆̆ıdır. Bu durum özellikle prospektif hasta takibinin zorluğu ve ölçümlerin zaman alması nedeni ile gönüllü hasta sayısının yetersiz olmasından kaynaklanmaktadır. İkinci olarak maliyet ve ulaşım zorluğu nedeni ile kuvvet ölçümü için elektromekanik dinamometre yerine el dinamometresi kullanılmıştır. $\mathrm{Bu}$ durum kısıtlılık olarak değerlendirilse de son zamanlarda yapılan birçok çalışmada "make test" tekniği kullanılarak el dinamometresi ile alt ekstremite kuvvet ölçümleri gerçekleştirilmiştir. Bir diğer kısıtlılığımız ise kullanılan subjektif skorlamalardan ODS’ nin Türkiye için validasyonu mevcutken ADC' nin validasyonunun olmamasıdır.

Sonuç olarak bu çalışma ile postoperatif kalça fleksiyon açıklı̆̆ ve fleksiyon kuvvetinin fonksiyonel durumu diğer objektif ölçümlere göre daha iyi yansıttığı görüldü. Ayrıca preoperatif kalça abduksiyon kuvvetinin postoperatif iyileşme ile korele olduğu görüldü. Bu veriler doğrultusunda rutin fizik tedavi programlarına ek olarak preoperatif kalça abduksiyonu ve postoperatif kalça fleksiyonuna yönelik egzersiz programları fonksiyonel iyileşmeyi artırmak için uygulanabilir. Bu durum örneklem sayısının daha büyük olduğu, kontrol gruplarının oluşturulduğu daha ileri prospektif randomize çalı̧̧malar ile desteklenmelidir. 


\section{Sakarya Tip Dergisi 2019;9(4):652-660}

1. Dulay GS, Cooper C, Dennison EM. Knee pain, knee injury, knee osteoarthritis \& work. Best Pract Res Clin Rheumatol. 2015; 29 (3): 454- 61.

2. National Institutes of Health Consensus Development Program. NIH Consensus Development Conference on Total Knee Replacement- Final Statement. NIH Consens State Sci Statements. 2003; 20 (1): 1- 34

3. Kim YH., Kim JS.. Does TKA Improve Functional Outcome and Range of Motion in Patients with Stiff Knees? Clin Orthop Relat Res. 2009; 467: 1348- 1354

4. Wylde V., Beswick A., Bruce J., Blom A., Howells N., Gooberman-Hill R.. Chronic pain after total knee arthroplasty. EFORT Open Rev. 2018; 3 (8): 461- 470.

5. Matsuda S., Kawahara S., Okazaki K., Tashiro Y., Iwamoto Y. Postoperative Alignment and ROM Affect Patient Satisfaction After TKA. Clin Orthop Relat Res. 2013; 471 (1): 127- 133.

6. Seynnes O, Hue OA, Garrandes F, Colson SS, Bernard PL, Legros $P$ et al. Force steadiness in the lower extremities as an independent predictor of functional performance in older women. J Aging Phys Act. 2005; 13: 395- 408.

7. Matharu GS, McBryde CW, Robb CA, Pynsent PB. An analysis of Oxford hip and knee scores following primary hip and knee replacement performed at a specialist centre. Bone Joint J. 2014; 96 (7): 928- 35.

8. Asif S, Choon DS. Midterm results of cemented Press Fit Condylar Sigma total knee arthroplasty system. J Orthop Surg. 2005; 13 (3): 280- 4

9. Alnahdi AH, Zeni JA, Snyder-Mackler L. Hip abductor strength reliability and association with physical function after unilateral total knee arthroplasty: a cross-sectional study. Phys Ther. 2014; 94 (8): 1154- 62

10. Mizner RL, Petterson SC, Snyder-Mackler L. Quadriceps strength and the time course of functional recovery after total knee arthroplasty. J Orthop Sports Phys Ther. 2005; 35 (7): 424- 36

11. Wyldea V., Lenguerranda E., Bruntona L., Dieppeb P., Gooberman-Hilla R., Mannc C, Bloma A.W. Does measuring the range of motion of the hip and knee add to the assessment of disability in people undergoing joint replacement? Orthop Traumatol Surg Res. 2014; 100 (2): $183-6$.

12. Mark D. Kohn, Adam A. Sassoon and Navin D. Fernando. Classifications in Brief: Kellgren-Lawrence Classification of Osteoarthritis. Clin Orthop Relat Res. 2016; 474 (8): $1886-$ 1893.

13. Lavernia C., D’Apuzzo M., Rossi M.D., Lee D. Accuracy of Knee Range of Motion Assessment After Total Knee Arthroplasty. J. Arthroplasty 2008; 23 (6): 85-91

14. Wudbhav N. Sankar, Christopher T. Laird and Keith D. Baldwin. Hip Range of Motion in Children: What Is the Norm? J Pediatr Orthop 2012; 32: 399- 405.

15. Livingstone C.; Joint motion: methods of measuring and recording. 6th ed. Edinburg: 1972 American Academy Of Orthopaedic Surgeons.

16. Caliskan. E, Saygi E.K., Gencer Z.K., Kurtel H., Erol B. Analysis of Postural Stability and Daily Energy Expenditure to Manage Tumor Patients' Functional Expectation. Clin Orthop Surg 2018; 10( 4): 491- 499

17. Sahin G. The assessment methods of physical activity level in elderly. Turk J Geriatr. 2010; 14 (2): $172-178$.

18. Thorborg K, Petersen J, Magnusson SP, Holmich P. Clinical assessment of hip strength using a hand-held dynamometer is reliable. Scand J Med Sci Sports. 2010; 20 (3): 493- 501

19. Insall JN, Dorr LD, Scott RD, Scott WN. Rationale of the Knee Society clinical rating system. Clin Orthop Relat Res. 1998; (248): 13- 4

20. Dawson J, Fitzpatrick R, Murray D, Carr A. Questionnaire on the perceptions of patients about total knee replacement. J Bone Joint Surg. 1998; 80 (1): 63-9.

21. Tuğay BU, Tuğay N, Güney H, Kınıkl Gİ, Yüksel İ, Atilla B. Oxford Knee Score: cross-cultural adaptation and validation of the Turkish version in patients with osteoarthritis of the knee. Acta Orthop Traumatol Turc. 2016; 50 (2): 198- 206.

22. Aboltins CA, Berdal JE, Casas F, Corona PS, Cuellar D, Ferrari MC et al. Hip and Knee Section, Prevention, Antimicrobials (Systemic): Proceedings of International Consensus on Orthopedic Infections. J Arthroplasty. 2019; 34 (2): 279- 288

23. Liao CD, Huang YC, Lin LF, Chiu YS, Tsai JC, Chen CL, Liou TH. Continuous passive motion and its effects on knee flexion after total knee arthroplasty in patients with knee osteoarthritis. Knee Surg Sports Traumatol Arthrosc. 2016; 24 (8): 2578- 86.

24. Xia ZN, Zhou Q, Zhu W, Weng XS. Low molecular weight heparin for the prevention of deep venous thEHAbosis after total knee arthroplasty: A systematic review and meta-analysis. Int J Surg. 2018; 54: 265- 275 .
25. Eksioglu E, Gurcay E. Total diz artroplastisi sonrast rehabilitasyon. Rehabilitation after total knee arthroplasty. J Ist Faculty Med. 2013; 76: 1.

26. Furu M, Ito H, Nishikawa T, Nankaku M, Kuriyama S, Ishikawa $M$ et al. Quadriceps strength affects patient satisfaction after total knee arthroplasty. J Orthop Sci. 2016; 21 (1): 38- 43 .

27. Kamenaga T, Muratsu H, Kanda Y, Miya H, Kuroda R, Matsumoto T. The Influence of Postoperative Knee Stability on Patient Satisfaction in Cruciate-Retaining Total Knee Arthroplasty. J Arthroplasty. 2018; 33 (8): 2475- 2479.

28. Abram SG, Nicol F, Spencer SJ. Patient reported outcomes in three hundred and twenty eight bilateral total knee replacement cases (simultaneous versus staged arthroplasty) using the Oxford Knee Score. Int Orthop. 2016; 40 (10): 2055- 2059.

29. West JA, Scudday T, Anderson S, Amin NH. Clinical outcomes and patient satisfaction after total knee arthroplasty: a follow-up of the first 50 cases by a single surgeon. J Int Med Res. 2019; 47 (4): 1667- 1676.

30. Minator Sajjadi M, Keyhani S, Kazemi SM, Hanafizadeh B, Ebrahimpour A, Banasiri M Patient Satisfaction Following Total Knee Arthroplasty: Comparison of Short-Term Results in Rheumatoid Arthritis and Osteoarthritis. Arch Bone Jt Surg. 2019; 7 (1): 61- 66.

31. Dawson J, Fitzpatrick R, Murray D, Carr A. Questionnaire on the perceptions of patients about total knee replacement. J Bone Joint Surg Br. 1998; 80 (1): 63- 9.

32. Osinski T, Bekka S, Regnaux JP, Fletcher D, Martinez V. Functional recovery after knee arthroplasty with regional analgesia: A systematic review and meta-analysis of randomised controlled trials. Eur J Anaesthesiol. 2019; 36 (6): 418- 426.

33. Aljehani M, Madara K, Snyder-Mackler L, Christiansen C, Zeni JA Jr. The contralateral knee may not be a valid control for biomechanical outcomes after unilateral total knee arthroplasty. Gait Posture. 2019; (70): 179- 184.

34. De Vroey H, Staes F, Weygers I, Vereecke E, Van Damme G, Hallez H et al. Hip and knee kinematics of the forward lunge one year after unicondylar and total knee arthroplasty. $J$ Electromyogr Kinesiol. 2019; (6) 48: 24- 30.

35. Kerrigan DC, Todd MK, Della Croce U, Lipsitz LA, Collins JJ. Biomechanical gait alterations independent of speed in the healthy elderly: evidence for specific limiting impairments. Arch Phys Med Rehabil. 1998; 79: 317- 322.

36. Al-Zahrani KS, Bakheit AMO. A study of the gait characteristics of patients with chronic osteoarthritis of the knee. Disabil Rehabil. Taylor \& Francis: 2002; 24: 275- 280.

37. Biggs PR, Whatling GM, Wilson C, Metcalfe AJ, Holt CA. Which osteoarthritic gait features recover following total knee replacement surgery? PLoS One. 2019: 25; 14 (1).

38. Ouellet D, Moffet H. Locomotor deficits before and two months after knee arthroplasty Arthritis Rheum. 2002; 47 (5): 484- 93.

39. Mutsuzaki H, Takeuchi R, Mataki Y, Wadano Y. Target range of motion for rehabilitation after total knee arthroplasty. J Rural Med. 2017; 12 (1): 33- 37.

40. Saleh KJ, Lee LW, Gandhi R, Ingersoll CD, Mahomed NN, Sheibani-Rad S. Quadriceps strength in relation to total knee arthroplasty outcomes. Instr Course Lect. 2010; 59: 119- 30.

41. Maempel JF, Clement ND, Brenkel IJ, Walmsley PJ. Range of movement correlates with the Oxford knee score after total knee replacement: A prediction model and validation. Knee. 2016; 23 (3): 511- 6.

42. Kurowicki J, Khlopas A, Sodhi N, Newman JM, Sultan AA, Chughtai M. Quadriceps and Hamstring Muscle Strength Improves After Unicompartmental Knee Arthroplasty. Surg Technol Int. 2017: 9; 31: 267-271

43. Miner AL, Lingard EA, Wright EA, Sledge CB, Katz JN. Knee range of motion after total knee arthroplasty: how important is this as an outcome measure? J Arthroplasty. 2003; 18 (3): $286-94$.

44. Jiang C, Zhang WK, Jiang Y, Chen LQ. Case-control study of influence factors analysis on short-term recovery after total knee arthroplasty in old patients with osteoarehritis. Zhongguo Gu Shang. 2012; 25 (5): 377- 9.

45. Brown M, Sinacore D.R, Binder E.F, Kohrt W.M. Physical and performance measures for the identification of mild to moderate frailty. J Gerontol A Biol Sci Med Sci. 2000; 55 (6): 350- 355.

46. Neumann D.A. Kinesiology of the hip: A focus on muscular actions. J. Orthop. Sports Phys. Ther. 2010; 40 (2): $82-94$

47. Semciw A.I., Pizzari T., Murley G.S., Green R.A. Gluteus medius: An intramuscular EMC investigation of anterior, middle and posterior segments during gait. J. Electromyogr. Kinesiol. 2013; 23 (4): $858-864$. 